Article

\title{
Effect of Sodium Hexametaphosphate and Trisodium Phosphate on Dispersion of Polycarboxylate Superplasticizer
}

\author{
Yan Zhang *, Huaqing Liu, Jialong Liu and Ruiming Tong \\ China Electric Power Research Institute, Beijing 100192, China; lhq@epri.sgcc.com.cn (H.L.); \\ liujialong@epri.sgcc.com.cn (J.L.); tongrm@epri.sgcc.com.cn (R.T.) \\ * Correspondence: zhangyan3@epri.sgcc.com.cn
}

Received: 8 September 2019; Accepted: 26 October 2019; Published: 13 December 2019

check for updates

\begin{abstract}
Enhancement in dispersion of polycarboxylate superplasticizer (PCE) could be obtained by incorporating retarders in normal concrete. The generally believed reason was that the consumption of free water and polymer at the beginning was reduced by retarding cement hydration. This theory could not convincingly explain why sodium hexametaphosphate (SHMP) was able to promote the dispersion capacity of PCE, while trisodium phosphate (TSP) could not, despite that both TSP and SHMP could obviously retard the cement hydration. The adsorption behavior of PCE and phosphate was investigated and the mechanism was analyzed in order to gain deeper understanding. The results showed that TSP and SHMP delayed the cement hydration, impeded adsorption process of PCE, and increased thickness of adsorption layer. It was interesting that TSP reduced the dispersion, but SHMP enhanced. The reason for this contradiction was due to the difference in composition of adsorption layer. In the PCE-TSP system, this layer was composed of the precipitates (formed by TSP and $\mathrm{Ca}^{2+}$ ) and the invalided PCE (caused by these precipitates in the immediate vicinity of the cement grains); the invalided PCE was due to the decrease of PCE dispersion. In the PCE-SHMP system, "Inner-phosphate (multi-layers) + Outer-PCE (single layer)" structure was formed to make the PCE work more effective, hence enhancing the dispersion. These results were expected to be useful for the design of highly efficient dispersants.
\end{abstract}

Keywords: phosphate; precipitation; adsorption; combination; adsorption layer; interface

\section{Introduction}

In recent years, high fluidity cement-based materials have been widely used in self-compacting concrete, pumping concrete, indoor floor, and grout, mainly because the superior workability could obtain the highly efficient construction process [1-6]. However, how to efficiently disperse the cement particles and obtain excellent fluidity performance without any bleeding and segregation is essential for this kind of material [7,8], and it also ensured the durability of concrete [9-12]. Generally, high fluidity can be easily achieved by incorporation of the comb-type copolymers, known as polycarboxylate superplasticizer (PCE) system [13-16], and this system consists of copolymers and retarders, rather than a single-component system [17-19]. In spite of being added as a supplementary material, retarders can significantly enhance the dispersion capacity of the superplasticizer system [20,21], and, in the real engineering practice, this has been widely employed. The generally believed reason is because the consumed free water and superplasticizer was reduced, as a result of the delayed hydration of cement minerals [22-25]. However, it has been proven that polyethylene oxide (PEO) side chains offer the main dispersion force (i.e., steric hindrance). It is noted that the polymer cannot exert dispersion unless it can adsorb on the surface of cement grains (i.e., S-PCE), and more S-PCE would provide higher 
dispersion capacity [26-30]. Based on this, the retarder might hinder the adsorption process of PCE and it was referred to as competitive adsorption [31-35], thereby reducing the dispersion. In addition, the thickness of the adsorption layer should also be accepted as a factor influencing the dispersion of PCE [36,37]. In spite of the decline in adsorption amount of PCE in the presence of retarder, as reported in previous study, the adsorption layer was obviously thickened to enhance the dispersion [37]. On the basis of discussion above, the conclusion could be made that the dispersion capacity of the PCE-retarder system should be associated with the retarding effect of retarder, adsorption behavior of PCE, and the thickness of the adsorption layer.

Poly-phosphates, such as sodium tripolyphosphate and sodium hexametaphosphate (SHMP), have been widely used to promote the dispersion ability and dispersion retention ability of the superplasticizer system in real engineering practice. However, mono-phosphates, such as trisodium phosphate (TSP) and sodium hydrogen phosphate, cannot play the same roles as poly-phosphate in commercially available PCE products. If the retardation was the main reason for the enhancement, poly-phosphate and mono-phosphate would both have a similar effect on dispersion of PCE system, because both TPS and SHMP could retard the cement hydration [38]. Therefore, the reason why the poly-phosphate could effectively enhance the dispersion, whilst the mono-phosphate failed cannot be simply explained by the retarding effect. One possible explanation might be attributed to the difference in the molecular structure of the phosphates, which could result in different performance at the water/solid interface during the very early-stage hydration [39-42], and this would further influence the adsorption layer [43-45]. As a consequence, the difference in PCE adsorption behavior could be expected in the presence of different phosphates.

In this study, the dispersion mechanism of the PCE-phosphate system was investigated. The rheology of cement paste was tested to evaluate the dispersion capacity of PCE-phosphate system. Adsorption behavior, including adsorption amount and thickness of adsorption layer, was analyzed to evaluate the water/solid interface performance of cement particles. The adsorption model was also proposed and the dispersion mechanism behind was revealed. Such results were expected to provide guidance regarding how to promote the dispersion capacity of PCE system in the future.

\section{Experimental}

\subsection{Materials}

\subsubsection{Cement}

An ordinary Portland cement (P. O. 42.5, supplied by Yadong Co., Ltd., Wuhan, China), in accordance with the requirements of GB 175-2007 Chinese standard, was used, and Table 1 shows the chemical compositions.

Table 1. Chemical composition of cement.

\begin{tabular}{|c|c|c|c|c|c|c|c|c|c|c|}
\hline & & LOI. & $\mathrm{SiO}_{2}$ & $\mathrm{Al}_{2} \mathrm{O}_{3}$ & $\mathrm{Fe}_{2} \mathrm{O}_{3}$ & $\mathrm{SO}_{3}$ & $\mathrm{CaO}$ & $\mathrm{MgO}$ & $\mathrm{K}_{2} \mathrm{O}$ & $\mathrm{Na}_{2} \mathrm{O}$ \\
\hline Cement & $\mathrm{wt} \%$ & 3.72 & 22.79 & 7.03 & 3.14 & 3.76 & 55.05 & 2.90 & 0.57 & 0.14 \\
\hline
\end{tabular}

\subsubsection{Polycarboxylate Superplasticizer}

Table 2 and Figure 1 show the basic performance and the molecular structure of PCE (the information was offered by HuanXuan Co., Ltd., Wuhan, China). From the figure, it was found that the mole ratio of carboxyl groups and long side chain was 3.5:1. Additionally, the polymerization degree of ethylene oxide was 48-52. 
Table 2. Basic performance of polycarboxylate superplasticizer (PCE).

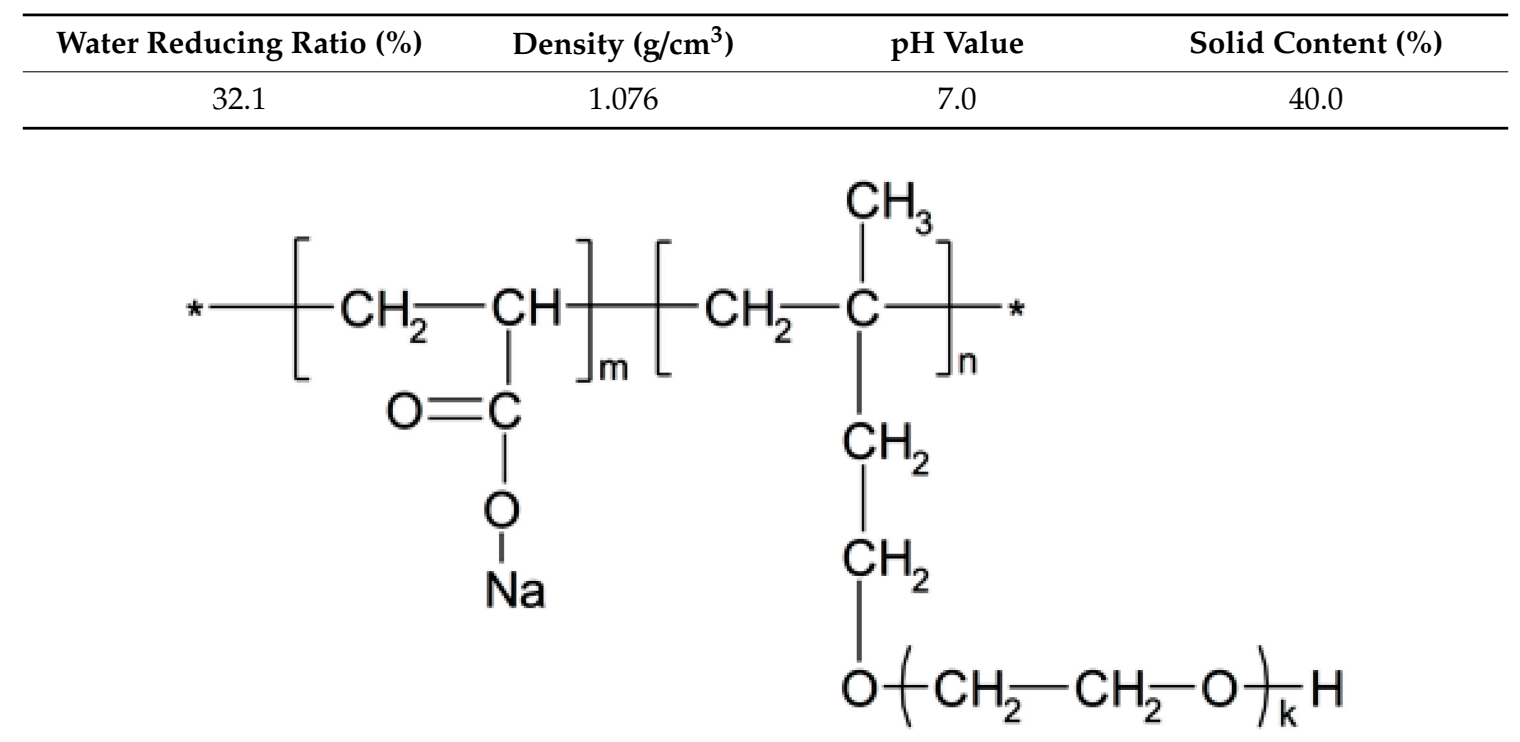

Figure 1. Molecular structure of polycarboxylate superplasticizer (PCE) (m:n = 3.5:1; $\mathrm{k}=48-52)$.

\subsubsection{Phosphates}

The reagent grade phosphates, including TSP $\left(\mathrm{Na}_{3} \mathrm{PO}_{4} \cdot 12 \mathrm{H}_{2} \mathrm{O}\right.$, the crystal water was considered in the experiment) and SHMP $\left(\mathrm{Na}_{6} \mathrm{P}_{6} \mathrm{O}_{18}\right.$, supplied by Sinopharm Chemical reagent Co., Ltd., Shanghai, China), were used. Figure 2 shows the molecular structures. From the figure, it was clearly observed that TSP is categorized as a mono-phosphate, while SHMP is a poly-phosphate.

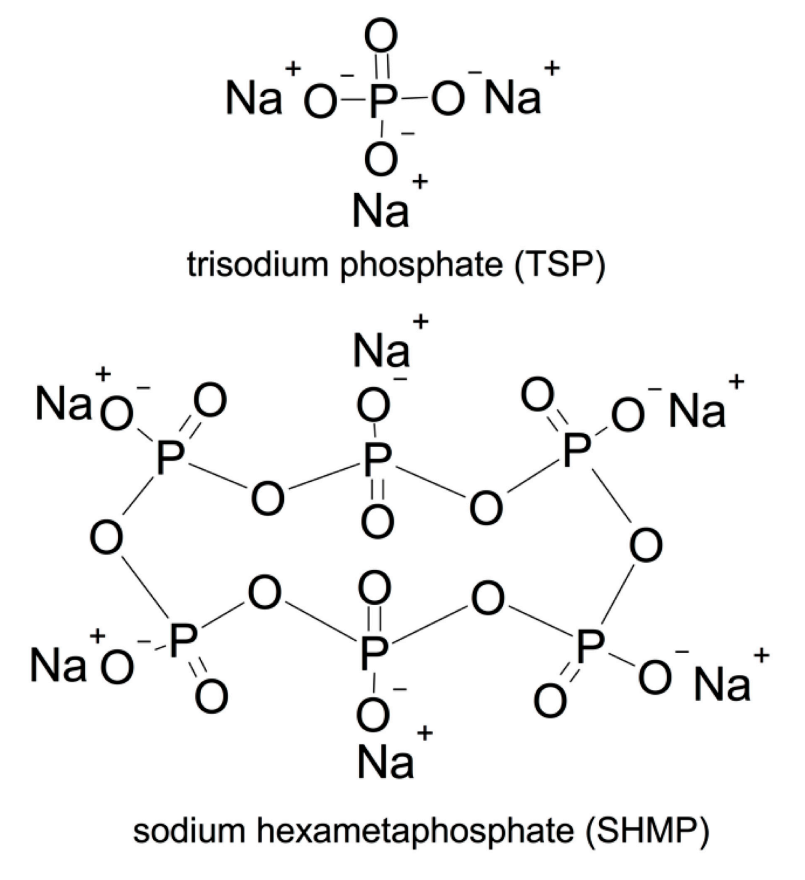

Figure 2. Molecular structure of phosphates.

\subsection{Test Methods}

\subsubsection{Rheology}

PCE and phosphate were added in water in advance, and the solution was then mixed with cement. Cement pastes in the presence of PCE-phosphate were prepared with 0.29 water/cement 
weight ratio (water: $87 \mathrm{~g}$, cement: $300 \mathrm{~g}$ ), and 0.44 water/cement weight ratio was used in pastes with phosphate, in accordance with the requirements of Chinese standard GB 8076-2008.

The rheology was evaluated by Rotor rheometer (R/S-SST, rotor: CC45, made by Brookfield, WI, USA). To reach a reference, the paste was firstly pre-sheared at a shear rate of $120 \mathrm{~s}^{-1}$ for $30 \mathrm{~s}$, and a shear rate was then directly applied from $0-100 \mathrm{~s}^{-1}$ within $120 \mathrm{~s}$, followed by a shear rate from $100-0 \mathrm{~s}^{-1}$ within $60 \mathrm{~s}$. Rheo 2000 V2.8 software (supplied by Brookfield, Middleboro, MA, USA) was used to process the data, and each flow curve was fitted with Bingham model and the value of yield stress and plastic viscosity was calculated.

\subsubsection{Adsorption Amount}

Phosphate solutions $(0.20 \mathrm{~g} / \mathrm{L}, 0.40 \mathrm{~g} / \mathrm{L}, 0.80 \mathrm{~g} / \mathrm{L}$, and $1.20 \mathrm{~g} / \mathrm{L})$ were prepared in advance and the phosphor content of the solution was examined by inductive coupled plasma emission spectrometer (ICP, Optima 4300 DV, made by Perkin Elmer Ltd., Wellesley, MA, USA). With the same step, total organic carbon analyzer examined carbon content (TOC, Liquid TOC II, made by Elementar, Germany). Figure 3 presents the results. Based on these results, the concentration of phosphate or PCE in solution was calculated with the phosphor content and carbon content tested by ICP and TOC, respectively.

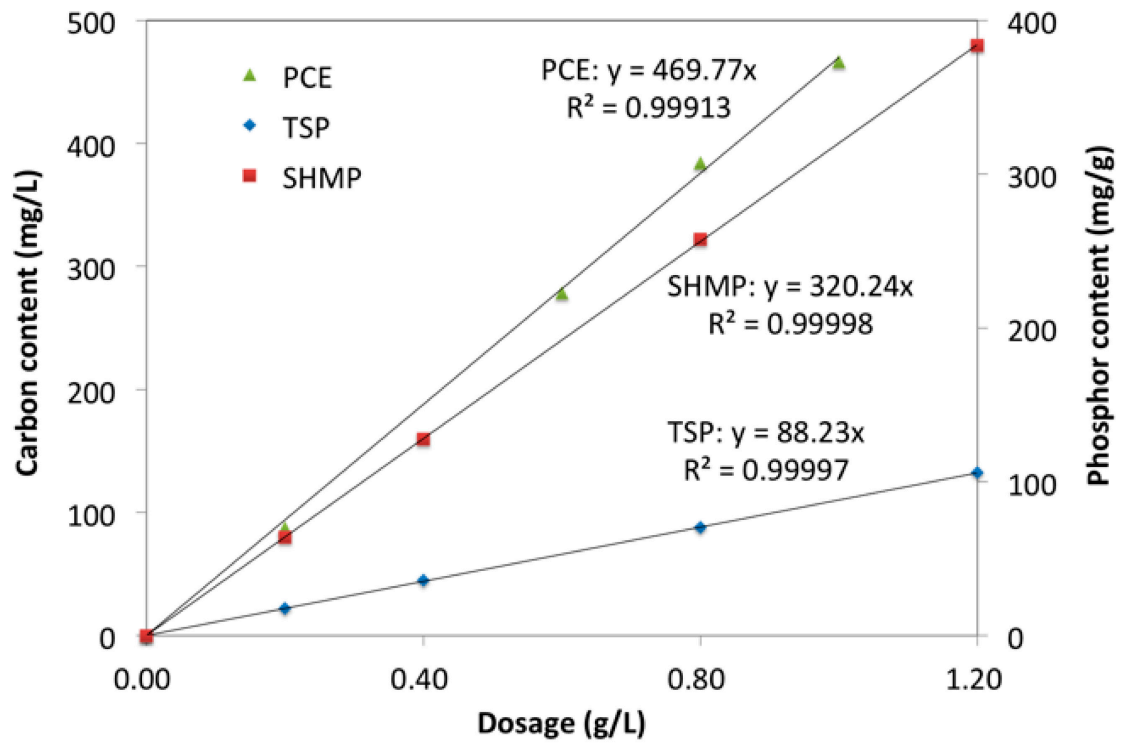

Figure 3. Relationship between concentration and tested results.

The solutions (20.0 g, components are shown in Table 3) were prepared in advance. These solutions and cement $(1.0 \mathrm{~g})$ were mixed together and stirred for $5 \mathrm{~min}$., respectively. The suspension was separated by centrifugation at $3000 \mathrm{r} / \mathrm{min}$ for $4 \mathrm{~min}$. The solid was dried in a vacuum at $25^{\circ} \mathrm{C}$ and then prepared for the measurement of X-ray photoelectron spectrometer (XPS), and the upper supernatant was prepared for the measurements of TOC and ICP. Three times text was done in each measurement, and the average was the results. Based on those results shown in Figure 3, the concentration of PCE and phosphate in the upper supernatant (i.e., residual concentration) was obtained from the results of TOC and ICP. The adsorption amount (mg/g-cement) and adsorption ratio was calculated, as follows:

$$
\begin{gathered}
\text { Adsorption amount }=\mathrm{V}\left(\mathrm{C}_{0}-\mathrm{C}\right) / \mathrm{m} \\
\text { Adsorption ratio }=\left(\mathrm{C}_{0}-\mathrm{C}\right) / \mathrm{C}_{0}
\end{gathered}
$$

where, $C_{0}$ represented the concentration of PCE or phosphates before adsorption, $g / L ; C$ denoted the concentration after adsorption, $\mathrm{g} / \mathrm{L} ; \mathrm{V}$ was the volume of the solution, $\mathrm{mL} ; \mathrm{m}$ was the mass of the cement, g. 
Table 3. Solutions prepared in advance for adsorption measurement.

\begin{tabular}{cccc}
\hline & PCE $(\mathrm{g} / \mathrm{L})$ & TSP $(\mathrm{g} / \mathrm{L})$ & SHMP $(\mathrm{g} / \mathrm{L})$ \\
\hline Single-component system & 1.00 & $0-2.0$ & \\
& & & $0-2.0$ \\
\hline Binary-component system & 1.00 & $0-2.0$ & $0-2.0$ \\
\hline
\end{tabular}

\subsubsection{Adsorption Layer}

The surficial silicon and calcium were tested by X-ray photoelectron spectrometer (XPS, XSAM 800, made by KRATOS, England, UK); aluminum was used as an anode target ( $h v=1486.6 \mathrm{eV})$; energy resolution was $0.100 \mathrm{eV}$. XPSPEAK 4.1 was used to process the data of XPS. The change of the binding energy of Ca2p indicated that the chemical bond of calcium on cement surface was altered, which provided evidence to prove the formation of the new type calcium-based compound. Furthermore, the adsorption layer could cover the silicon layer and reduce the intensity of the photoelectron. The relationship between the thickness of adsorption layer and intensity of photoelectron was shown, as follows:

$$
\begin{gathered}
\mathrm{I}(\mathrm{b})=\mathrm{I}_{0} \exp \left[-\mathrm{b} / \lambda\left(\mathrm{E}_{\mathrm{k}}\right)\right] \\
\lambda\left(\mathrm{E}_{\mathrm{k}}\right)=49 \mathrm{E}_{\mathrm{k}}^{2}+0.11\left(\mathrm{E}_{\mathrm{k}}\right)^{1 / 2} \\
\mathrm{E}_{\mathrm{k}}=h v-\mathrm{E}_{\mathrm{b}}
\end{gathered}
$$

where,

$\mathrm{I}_{0}$ denoted the initial photoelectron intensity;

I(b) represented the photoelectron intensity after the photoelectron went through the adsorption layer; meant the thickness of adsorption layer, $\mathrm{nm}$;

$\mathrm{E}_{\mathrm{k}}$ was the photoelectron kinetic energy after the photoelectron went through the adsorption layer, eV; $\mathrm{E}_{\mathrm{b}}$ was the electron binding energy, $\mathrm{eV}$.

Based on this, the thickness of adsorption layer could be calculated from the XPS data of silicon [37].

\subsubsection{Hydration Heat}

Phosphates ( $0.20 \mathrm{wt} \%$ of cement) were added into water in advance, respectively; and then, the paste was prepared with a water/cement weight ratio of $0.35: 1$. Hydration heat of cement paste was obtained by micro calorimeter.

\subsubsection{Phase Analysis}

Cement pastes with phosphates $(0.20 \mathrm{wt} \%$ of cement) were prepared with a 0.35 water/cement weight ratio. After being cured for one day under the room temperature $\left(20^{\circ} \mathrm{C}\right)$ and relative humidity (RH) higher than $90 \%$, they were broken into small pieces and then immersed in anhydrous ethanol to stop hydration. After that, the samples were dried under vacuum and ground to pass 63 um sieve. The powders are used for the measurement of X-ray Diffractometer (XRD, D/Max-RB, made by Rigaku, Japan) with $\mathrm{Cu}(\mathrm{K} \alpha)$ radiation and a current of $(40 \mathrm{~mA}, 40 \mathrm{kV})$, at a speed of $4^{\circ} / \mathrm{min}$. and a step of $0.02^{\circ}$ within the range of 5 to $70^{\circ}$.

\subsubsection{Conductivity Measurement}

The solution of calcium hydroxide (CH, $0.10 \mathrm{~g} / \mathrm{L})$, PCE $(0.1 \mathrm{~g} / \mathrm{L}, 10.0 \mathrm{~g} / \mathrm{L})$, SHMP $(1.0 \mathrm{~g} / \mathrm{L})$, and PCE-SHMP (PCE: $10.0 \mathrm{~g} / \mathrm{L}$, SHMP: $1.0 \mathrm{~g} / \mathrm{L}$ ) were prepared in advance. The conductivity of deionized water, PCE solution, SHMP solution, and PCE-SHMP solution with the increasing dosage of $\mathrm{CH}$ was 
examined with an electrical conductivity meter. The conductivity of deionized water and SHMP-CH with the increasing dosage of PCE was tested with the electrical conductivity meter. The reference was the deionized water. The different tendencies from the reference were able to illustrate the reaction happening in liquid phase.

\section{Results and Discussions}

\subsection{Rheology of Cement Paste Plasticized by PCE-Phosphate}

Figure 4 shows the yield stress and viscosity of cement paste in the presence of PCE-phosphate. As shown in Figure 4a, it was found that the yield stress of the paste with PCE-TSP was increased with the increasing dosage of TSP, while the plastic viscosity was slightly increased. This result illustrated that TSP declined the dispersion of PCE. It was obviously different from what it was expected that TSP should enhance the dispersion due to the retarding effect. Furthermore, in cement paste with the addition of PCE-SHMP, as shown in Figure $4 b$, the decline in yield stress was observed with the increasing dosage of SHMP, and this result indicated that SHMP could enhance the dispersion of PCE, which was opposite to the result of TSP. The plastic viscosity was firstly increasing and then reduced, and this phenomenon was revealed, as follows: on the one hand, due to the plasticizing effect, the agglomerated particles were dispersed, and finer particles in suspension was increased to promote the plastic viscosity $[46,47]$. On the other hand, the amount of free water in system would be increased to decrease the plastic viscosity due to the retarding effect. Accordingly, the predominated aspect should determine plastic viscosity. The increased stage of plastic viscosity indicated that the dispersion effect was predominated when the dosage of SHMP less than $0.10 \%$, while the decrease indicated that the retarding effect on hydration predominated when the added dosage was more than $0.10 \%$.

The effect of single phosphate system on the rheology of cement paste was also considered, and the results are shown, as follows:

From Figure 5a, it was found that the yield stress was slightly increased from 29.4 Pa to 33.5 Pa by adding TSP, while the plastic viscosity was almost kept constant. As shown in Figure 5b, the yield stress of the cement paste was declined by SHMP; this illustrated the plasticizing effect of SHMP, and the possible reason was the reduced consumption amount of free water originating from the delay of cement hydration and the increased zeta potential resulting from adsorption. Furthermore, the plastic viscosity was slightly reduced, and this was attributed to the delayed formation of hydration products and the reduced yield stress.

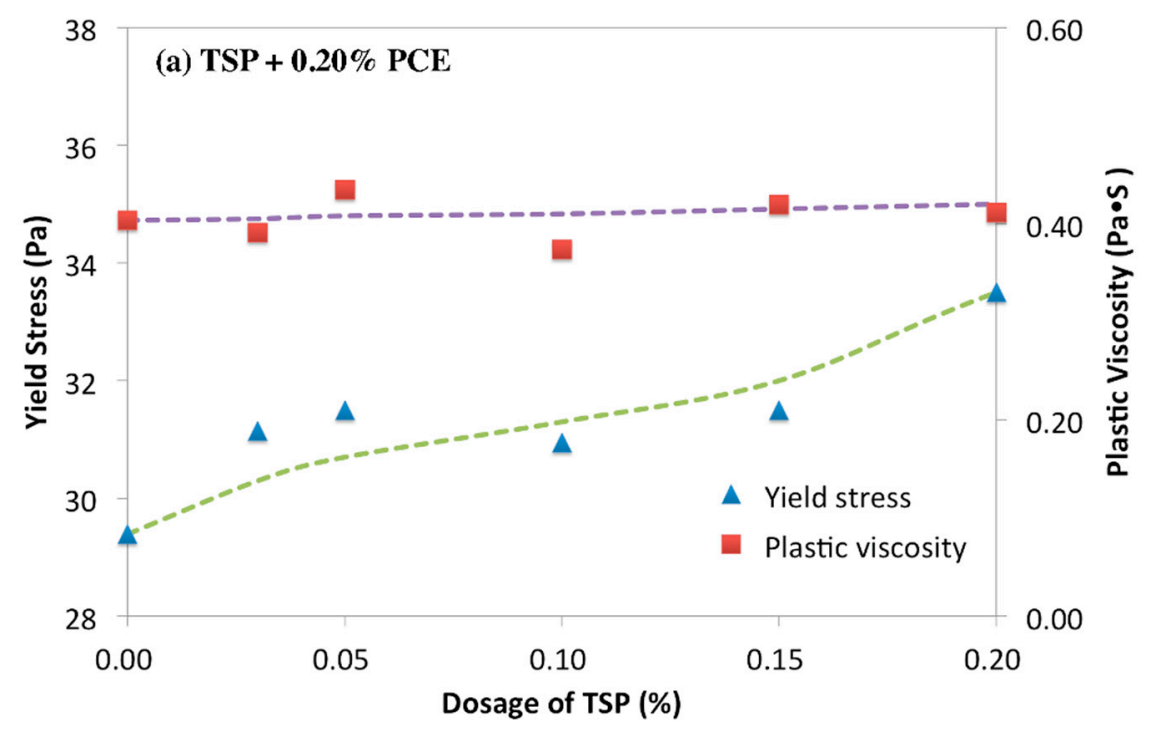

Figure 4. Cont. 


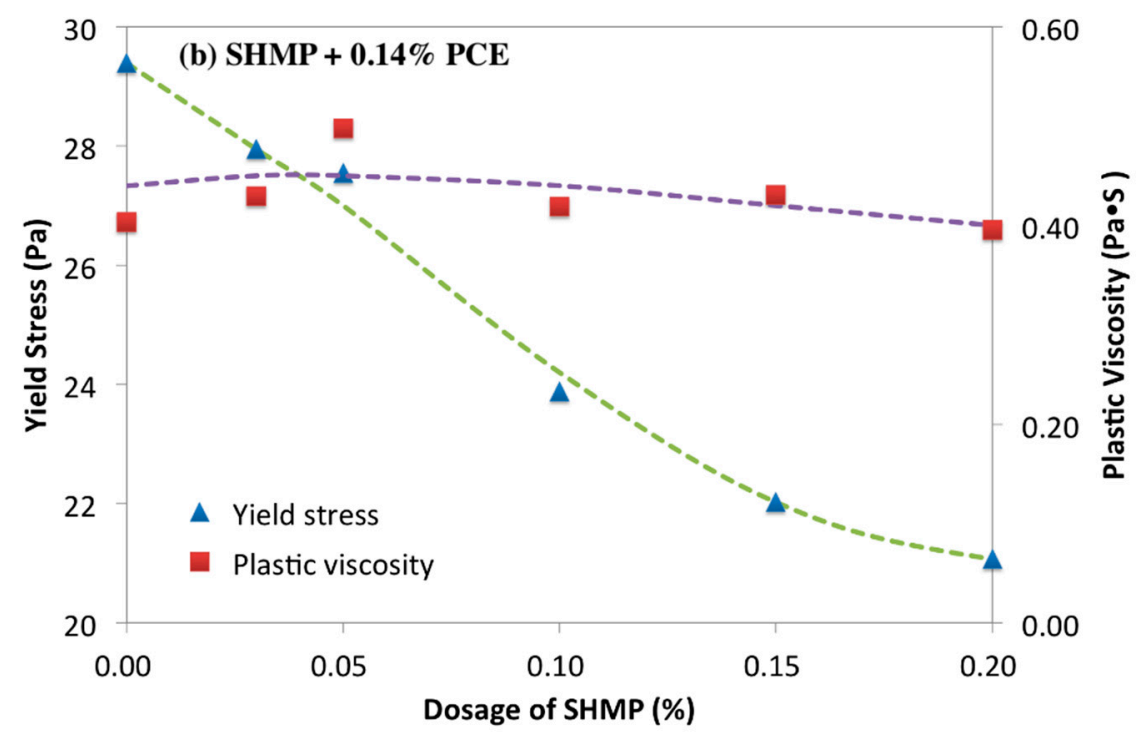

Figure 4. Rheology of cement paste with PCE-trisodium phosphate/sodium hexametaphosphate, (a) PCE-TSP; (b) PCE-SHMP.
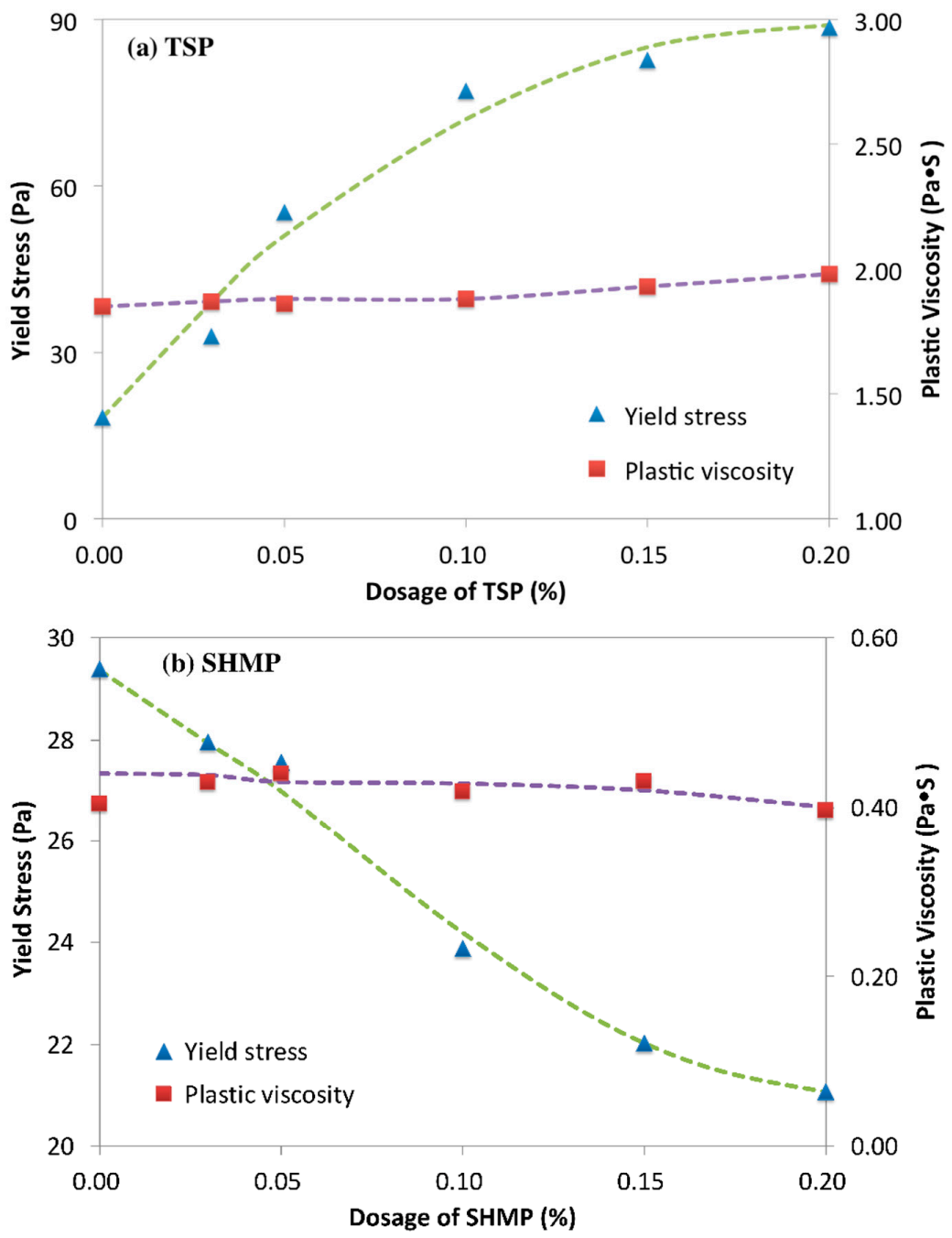

Figure 5. Yield stress and plastic viscosity of cement paste with TSP/SHMP, (a) TSP; (b) SHMP. 
On the basis of the discussion above, it was concluded that, in cement paste, SHMP showed the obvious plasticizing effect, but TSP not, and in PCE-phosphate system, dispersion of PCE was enhanced by SHMP, but reduced by TSP. This agreed with the practical experience. Conventionally, retarder could delay the cement hydration and hydrate formation, which would save free water to reduced yield stress of cement paste. This could explain the reduced yield stress by SHMP, but it could not reveal the reason for the reduced yield stress by TSP. In the PCE-phosphate system, the positive effect of SHMP on rheological performance could be explained from the retarding effect of SHMP, while that for TSP seemed contradictory.

\subsection{Retarding Effect of Phosphates on Cement Paste}

The noticeable difference in the retarding effect of the phosphates was clearly found from XRD and hydration heat. $\mathrm{CH}$ (i.e., calcium hydroxide) and AFt (i.e., ettringite) are considered as typical hydration products of Portland cement, and generally, the degree of hydration of the cement can be inferred from the amount of these two kinds of hydration products [48-51], which can be reflected in the characteristic peak in XRD. As shown in Figure 6, a much lower characteristic peak of $\mathrm{CH}$ and $\mathrm{AFt}$ than that of the reference was observed, indicating that both TSP and SHMP delay the hydration of the cement paste in the early age and SHMP showed stronger retarding effect than TSP. The same result was also found in the hydration heat, as shown in Figure 7. TSP and SHMP both delayed heat peak, but SHMP showed a stronger effect than TSP. This result also indicated that TSP and SHMP could both delay the cement hydration, and SHMP showed a stronger retarding effect than TSP; these results would be most likely related to the adsorption of chemicals [52,53].

From the discussion above, SHMP and TSP could both be deemed as retarder in the cement hydration process, and SHMP has stronger retarding effect than TSP. Based on conventional theory, both TSP and SHMP should enhance the dispersion of PCE, rather than that TSP reduced the dispersion. The enhancement could be explained reasonably, while the decline could not. As a consequence, the mechanism behind could not be only explained from retarding effect.

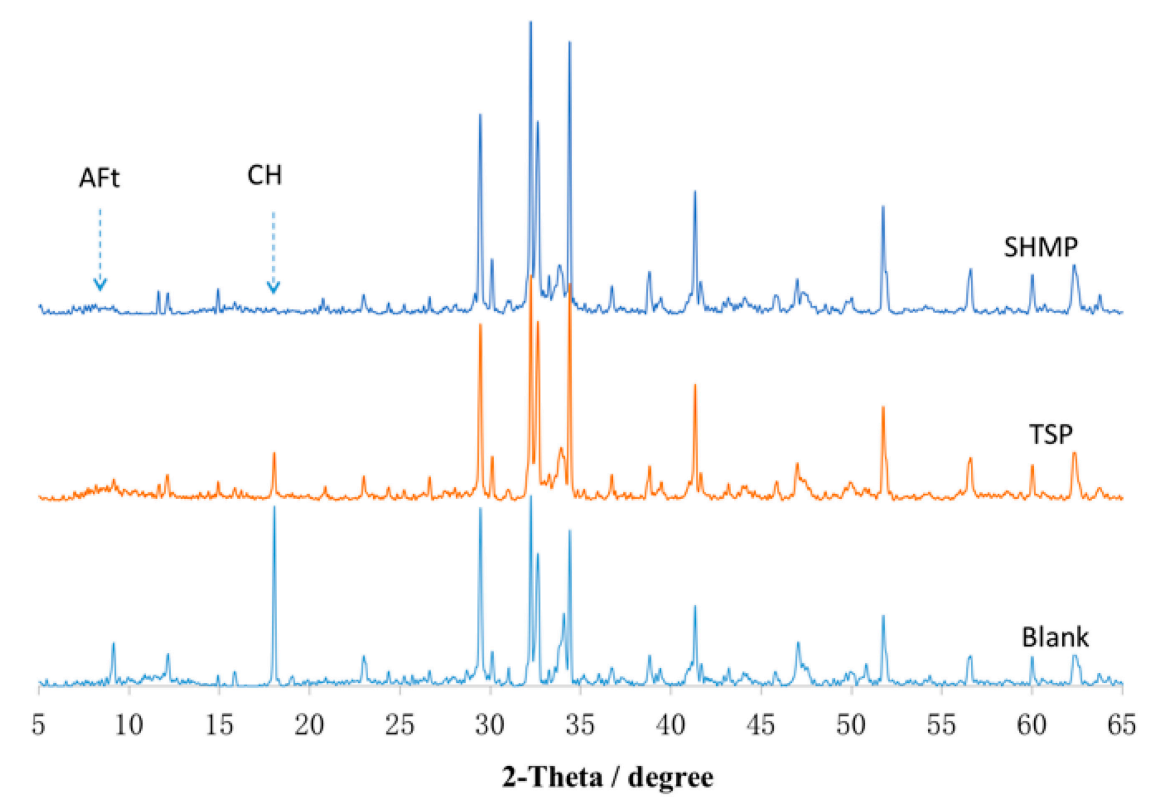

Figure 6. X-ray Diffractometer (XRD) pattern of cement paste with phosphate hydrating for $1 \mathrm{~d}$. 


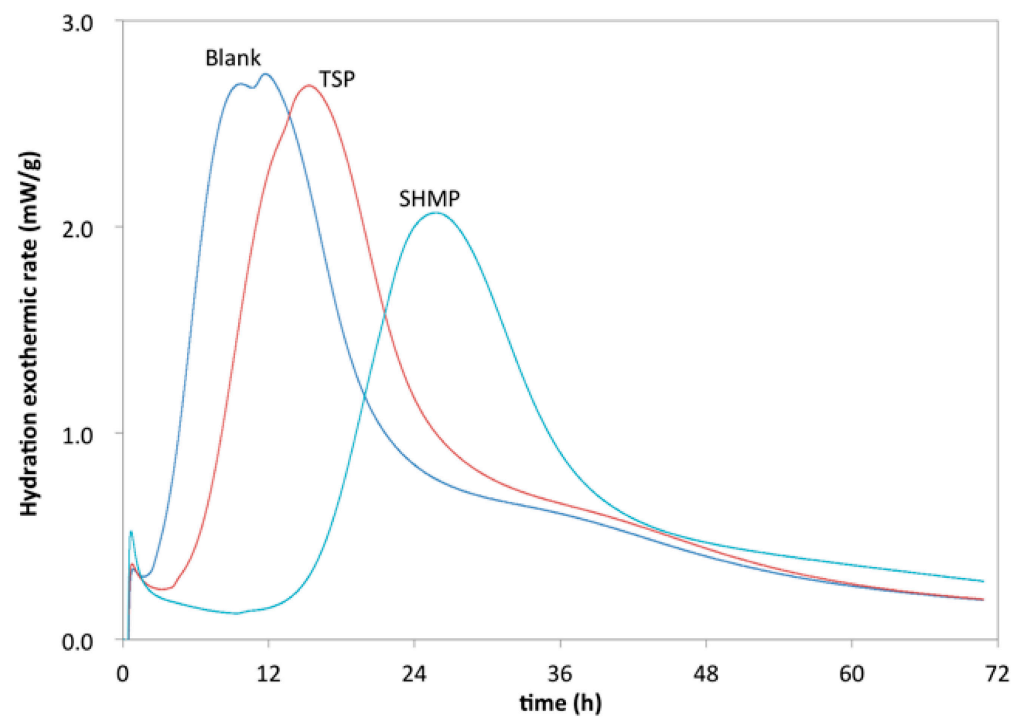

Figure 7. Hydration heat of the cement paste with phosphate.

\subsection{Adsorption Amount}

The adsorption amount of PCE has been reported to determine the dispersion ability of PCE [26]. In the presence of retarder, competitive adsorption would happen between PCE and retarder; it meant that the adsorption process of PCE would be hindered by the addition of phosphate, which resulted in a decline in the dispersion [20,31,54]. The adsorption amount of PCE in the presence of TSP and SHMP was tested in order to confirm the competitive adsorption, and Figure 8 shows the results. It was found that TSP and SHMP could both significantly decrease the adsorption amount of PCE, and the ability of SHMP to hinder PCE from adsorption was much stronger than that of TSP. This result illustrated that the dispersion ability of PCE should be reduced by the presence of phosphates. Based on this, the decrease in fluidity and increase in yield stress caused by PCE-TSP was reasonably explained. However, this could not reveal the reason for the opposite phenomenon with PCE-SHMP. As a consequence, this mechanism could not be simply explained by competitive adsorption as well.

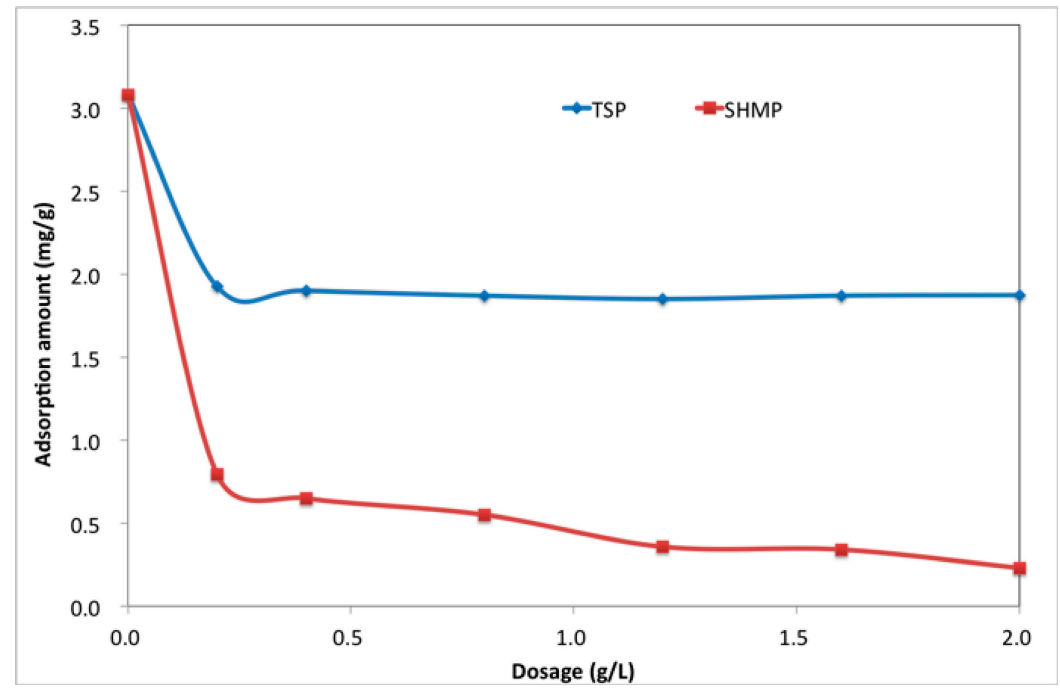

Figure 8. Effect of TSP and SHMP on adsorption of PCE (PCE: $1.0 \mathrm{~g} / \mathrm{L})$.

The adsorption behavior of phosphate in cement suspension was investigated to further discuss the competitive adsorption, and the results are shown in Figure 9. 




Figure 9. Adsorption of phosphate in cement suspension.

TSP and SHMP were both able to adsorb on the surface of the cement grains, and the adsorption ratio reached more than $95.0 \%$, which meant that the vast majority of the phosphate could adsorb onto the surface of the cement particles. In liquid phase, phosphates were quickly ionized and released the anions of $\left[\mathrm{PO}_{4}\right]^{3-}$ or $\left[\mathrm{P}_{6} \mathrm{O}_{18}\right]^{6-}$, with negative charge. On the one hand, because of electrostatic attraction resulting from the positive zeta potential of cement particles at the very beginning [55], the ionized phosphate could quickly adsorb onto the cement surface. On the other hand, the released $\mathrm{Ca}^{2+}$ into solution that was caused by cement hydration could be precipitated with $\left[\mathrm{PO}_{4}\right]^{3-}$ or be combined with $\left[\mathrm{P}_{6} \mathrm{O}_{18}\right]^{6-}$, which results in adsorption. In other words, the adsorption of TSP resulted from the precipitation with $\mathrm{Ca}^{2+}$ in the immediate vicinity of cement particles, and adsorption of SHMP was due to the combination with surficial $\mathrm{Ca}-\mathrm{O}$ or $\mathrm{Ca}^{2+}$. In that case, these phosphates occupied the adsorption point and, therefore, PCE could not adsorb on these points, which was inferred to be responsible for the reduced adsorption amount of PCE by adding phosphate.

In addition, the adsorption of phosphate would hinder the release of $\mathrm{Ca}^{2+}$ into the liquid phase. This hindrance was directly proved by $\mathrm{Ca}^{2+}$ concentration in pore solution, as displayed in Figure 10 . TSP and SHMP both reduced the concentration of $\mathrm{Ca}^{2+}$ in pore solution. Combined with the analysis of adsorption, the reduced concentration of $\mathrm{Ca}^{2+}$ indicated that the formation a calcium-based phosphate layer. It was this layer that resulted in the retarding effect of phosphate. Furthermore, this layer hindered the $\mathrm{Ca}^{2+}$ from being released into solution, thereby delaying the formation of hydration products; one the other hand, it isolated water from cement particles to hinder the cement hydration.

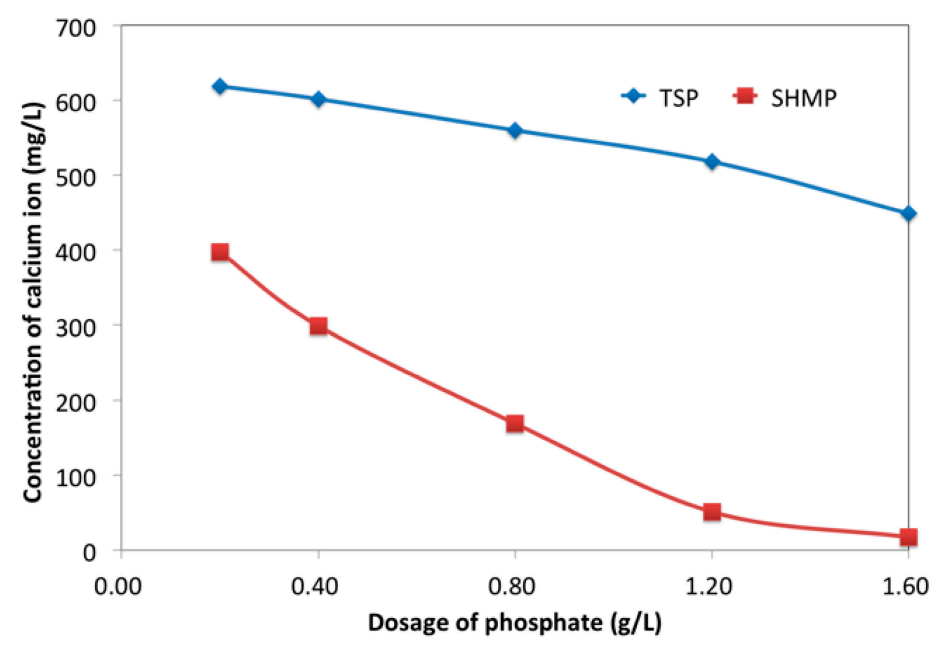

Figure 10. Effect of phosphates on $\mathrm{Ca}^{2+}$ in pore solution. 


\subsection{Thickness of Adsorption Layer}

The adsorption layer was reported to affect the dispersion ability of PCE and, generally, the thicker adsorption layer was able to provide a stronger dispersing ability $[54,56]$. Thickness of adsorption layer in the presence of PCE $(0.40 \mathrm{~g} / \mathrm{L})$ and phosphate $(0.40 \mathrm{~g} / \mathrm{L})$ was calculated from the XPS data of Si2p, and Table 4 shows the results. From the table, the strongest intensity of photoelectron was observed in the blank sample, and the decreased intensity of photoelectron in the presence of PCE or PCE-phosphate system indicated the existence of adsorption layer on the surface of the cement particles.

Table 4. Adsorption layer on the cement particles calculated from X-ray photoelectron spectrometer (XPS) data.

\begin{tabular}{ccccc}
\hline & Blank & TSP + PCE & SHMP + PCE & PCE \\
\hline$h v(\mathrm{eV})$ & 1486.60 & 1486.60 & 1486.60 & 1486.60 \\
$\mathrm{E}_{\mathrm{b}}(\mathrm{eV})$ & 101.98 & 101.97 & 101.97 & 101.97 \\
Height Counts & 1470.72 & 749.95 & 774.44 & 1013.12 \\
FWHM $(\mathrm{eV})$ & 2.72 & 2.03 & 2.00 & 2.62 \\
$\mathrm{I}_{0}$ & 4000.36 & & & \\
$\mathrm{I}(\mathrm{b})$ & & 1522.40 & 1548.88 & 2654.37 \\
$\mathrm{I} / \mathrm{I}_{0}$ & & 0.3805 & 0.3872 & 0.6635 \\
Ek & 1384.63 & 1384.63 & 1384.62 \\
$\lambda(\mathrm{Ek})$ & 4.0932 & 4.0932 & 4.0932 \\
Adsorption layer $(\mathrm{b}, \mathrm{nm})$ & & 3.95 & 3.88 & 1.68 \\
\hline
\end{tabular}

As shown in Table 4, TSP and SHMP in PCE system both increased the thickness of the adsorption layer, which might promote the dispersion capacity of the PCE-phosphate system. This could explain the increased dispersion ability of PCE-SHMP, but it was unclear why dispersing ability of PCE could not be promoted by adding TSP. As a consequence, the mechanism could not be simply explained by the thickness of adsorption layer.

\subsection{Composition of Adsorption Layer}

The composition of adsorption layer was further discussed to reveal the mechanism:

In the PCE system with TSP, the white precipitates were observed in the solution almost at the same time with the addition of calcium hydroxide solution $(\mathrm{CH}, 0.10 \mathrm{~g} / \mathrm{L})$. The solid in suspension was filtered and dried at about $25^{\circ} \mathrm{C}$ in order to confirm the chemical composition of the precipitate; then, these powders were tested by XRD. As shown in Figure 11, it was seen that the precipitate was composed of hydroxyapatite and calcium phosphate. This result indicated that hydroxyapatite and calcium phosphate would present on the surface of the cement grains.



Figure 11. XRD pattern of the precipitate. 
On the other hand, TSP could be precipitated with $\mathrm{Ca}^{2+}$ in solution at a very low concentration since the solubility product constant (Ksp) of the calcium phosphate (TCP, $\left.\mathrm{Ca}_{3}\left(\mathrm{PO}_{4}\right)_{2}\right)$ and hydroxyapatite $\left(\mathrm{AH}, \mathrm{Ca}_{10}\left(\mathrm{PO}_{4}\right)_{6}(\mathrm{OH})_{2}\right)$ is $2.07 \times 10^{-29}$ and $2.35 \times 10^{-59}$ at the room temperature [57]. It was well known that the $\mathrm{pH}$ value of cement suspension could exceed 12 immediately after the cement were mixed with water [55]. The concentration of $\mathrm{Ca}^{2+}$ was calculated to be about $0.001-0.005 \mathrm{~mol} / \mathrm{L}$; if the concentration of $\left[\mathrm{PO}_{4}\right]^{3-}$ was more than $1.0 \times 10^{-10} \mathrm{~mol} / \mathrm{L}$, the precipitation would take place. Obviously, the precipitate could be formed almost simultaneously with the release of the $\mathrm{Ca}^{2+}[58]$. This result provided enough evidence to prove that it was in the immediate vicinity of cement particles that the precipitation would happen. In that case, these precipitates most likely covered the PCE, which was adsorbed on the surface of the cement particles. Therefore, it was deduced that the adsorption layer should be composed of the mixed calcium-based phosphate and PCE polymer.

In PCE-SHMP system, SHMP was combined with $\mathrm{Ca}^{2+}$ rather than precipitated with $\mathrm{Ca}^{2+}$. The released hexametaphosphate ions were combined with the surficial $\mathrm{Ca}-\mathrm{O}$ or $\mathrm{Ca}^{2+}$ to form the complexes, thereby adsorbing onto the surface of the cement particles. They could also be combined with $\mathrm{Ca}^{2+}$, which presented in solution. One $\mathrm{Ca}^{2+}$ was combined at least two hexametaphosphate ions and then a net structure would be formed on surface of the cement particles. At the same time, $\mathrm{Ca}^{2+}$ was also combined with carboxyl groups of PCE, and it was possible that one PCE and one SHMP could be combined with one $\mathrm{Ca}^{2+}$. That was to say, one $\mathrm{Ca}^{2+}$ might bridge one SHMP and one PCE. The conductivity of the solution was tested with an electrical conductivity meter to further confirm the combination with $\mathrm{Ca}^{2+}$. In Figure 12, the conductivity of the reference (deionized water) was increased with the increasing dosage of $\mathrm{CH}(0.1 \mathrm{~g} / \mathrm{L})$, because of $\mathrm{OH}^{-}$and $\mathrm{Ca}^{2+}$ brought by $\mathrm{CH}$. For PCE, conductivity was first reduced and then increased. The decline indicated the consumption of the ion in solution, because $\mathrm{Ca}^{2+}$ was combined with carboxyl groups in PCE [59-61]. After almost all carboxyl groups were combined, the conductivity was increased. The same result was also seen in SHMP solution and PCE-SHMP solution, as shown in Figure 12. Furthermore, the combining capacity was calculated from the consuming amount of $\mathrm{CH}$ at the inflection point. The consumption of $\mathrm{CH}$ $(0.1 \mathrm{~g} / \mathrm{L})$ for PCE $(100 \mathrm{~g}, 10 \mathrm{~g} / \mathrm{L})$ as about $52 \mathrm{~g}$, about $30 \mathrm{~g}$ for SHMP $(100 \mathrm{~g}, 1.0 \mathrm{~g} / \mathrm{L})$, and about $56 \mathrm{~g}$ for PCE-SHMP (100g, $10.0 \mathrm{~g} / \mathrm{L} \mathrm{PCE}$ and $1.0 \mathrm{~g} / \mathrm{L}$ SHMP). If no interaction among PCE, SHMP, and $\mathrm{Ca}^{2+}$, the consumption of $\mathrm{CH}(0.1 \mathrm{~g} / \mathrm{L})$ for PCE-SHMP would be $80-90 \mathrm{~g}$ (i.e., the summation of the consumed $\mathrm{CH}$ by SHMP and PCE). In fact, that consumption for PCE-SHMP was merely a little more than that for PCE, being significantly different from what was expected. This result provided strong evidence to prove that the interaction among PCE, SHMP and $\mathrm{Ca}^{2+}$ took place. SHMP $(100 \mathrm{~g}, 1.0 \mathrm{~g} / \mathrm{L})$ was mixed with $\mathrm{CH}(30 \mathrm{~g}, 0.1 \mathrm{~g} / \mathrm{L})$ to further confirm this interaction; in this solution, the phosphate ions were almost completely combined with $\mathrm{Ca}^{2+}$ as SHMP-Ca (i.e., SHMP, which has been combined with $\left.\mathrm{Ca}^{2+}\right)$. Additionally, then, the conductivity of this solution with the increasing dosage of PCE solution $(0.10 \mathrm{~g} / \mathrm{L})$ was measured and the change tendency was discussed. In Figure 13, PCE increased the conductivity of reference (deionized water). However, the opposite pattern was observed in SHMP-CH solution. This phenomenon could further prove the interaction between PCE and SHMP-Ca. Based on discussion above, it was concluded that PCE could be combined with SHMP-Ca to form PCE-Ca-SHMP, which meant that, in the PCE-SHMP system, the bridging $\mathrm{Ca}^{2+}$ between SHMP and PCE was formed. In that case, SHMP could adsorb onto the SHMP layer via the bridging $\mathrm{Ca}^{2+}$, and PCE could also adsorb onto the surface of the SHMP layer, because of the combination with $\mathrm{Ca}^{2+}$ (SHMP-Ca-PCE). Therefore, it was inferred that the adsorption layer should compose a phosphate net structure inside and a PCE layer outside. 




Figure 12. Conductivity of PCE-SHMP with $\mathrm{CH}(0.1 \mathrm{~g} / \mathrm{L})$.

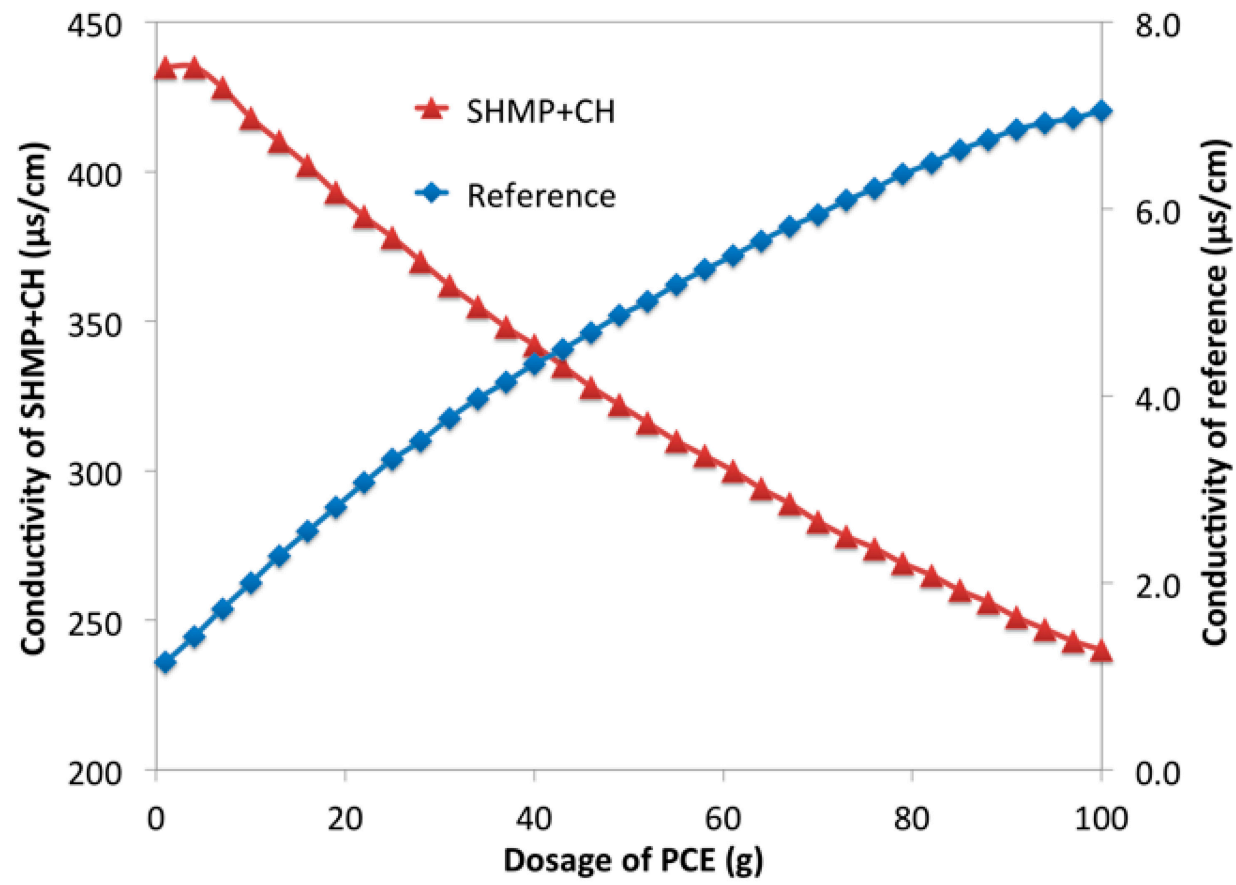

Figure 13. Conductivity of SHMP-CH with PCE $(0.1 \mathrm{~g} / \mathrm{L})$.

As mentioned above, in the PCE-phosphate system, the calcium-based phosphate layer was produced on the surface and, therefore, a new type of calcium-based compound would be formed on the surface of the cement particles, no matter whether precipitation or combination. If so, different binding energy of calcium from the blank would be expected. To confirm this, the binding energy of calcium was evaluated with XPS. As shown in Figure 14, the binding energy of Ca2 $\mathrm{p}_{3 / 2}$ was increased from $345.75 \mathrm{eV}$ in blank to $345.94 \mathrm{eV}$ in the presence of PCE, with an increase by $0.19 \mathrm{eV}$, which indicated the formation of PCE-Ca on the surface of the cement grains. PCE-TSP reduced the binding energy of $\mathrm{Ca} 2 \mathrm{p}_{3 / 2}$ by $0.43 \mathrm{eV}$, with a decrease by $0.21 \mathrm{eV}$ in binding energy of $\mathrm{Ca} 2 \mathrm{p}_{1 / 2}$. when compared with PCE. This result demonstrated that the calcium-based phosphate was formed on the surface of the cement particles. For PCE-SHMP, the peak shift of binding energy of Ca2 $\mathrm{p}_{1 / 2}$ was $0.18 \mathrm{eV}$ in comparison with that of PCE, which was caused by the formation of the complex, namely SHMP-Ca. 
As a consequence, the results of binding energy of Ca2p provided further evidence to confirm the precipitation or combination of phosphate with $\mathrm{Ca}^{2+}$ on the cement surface.

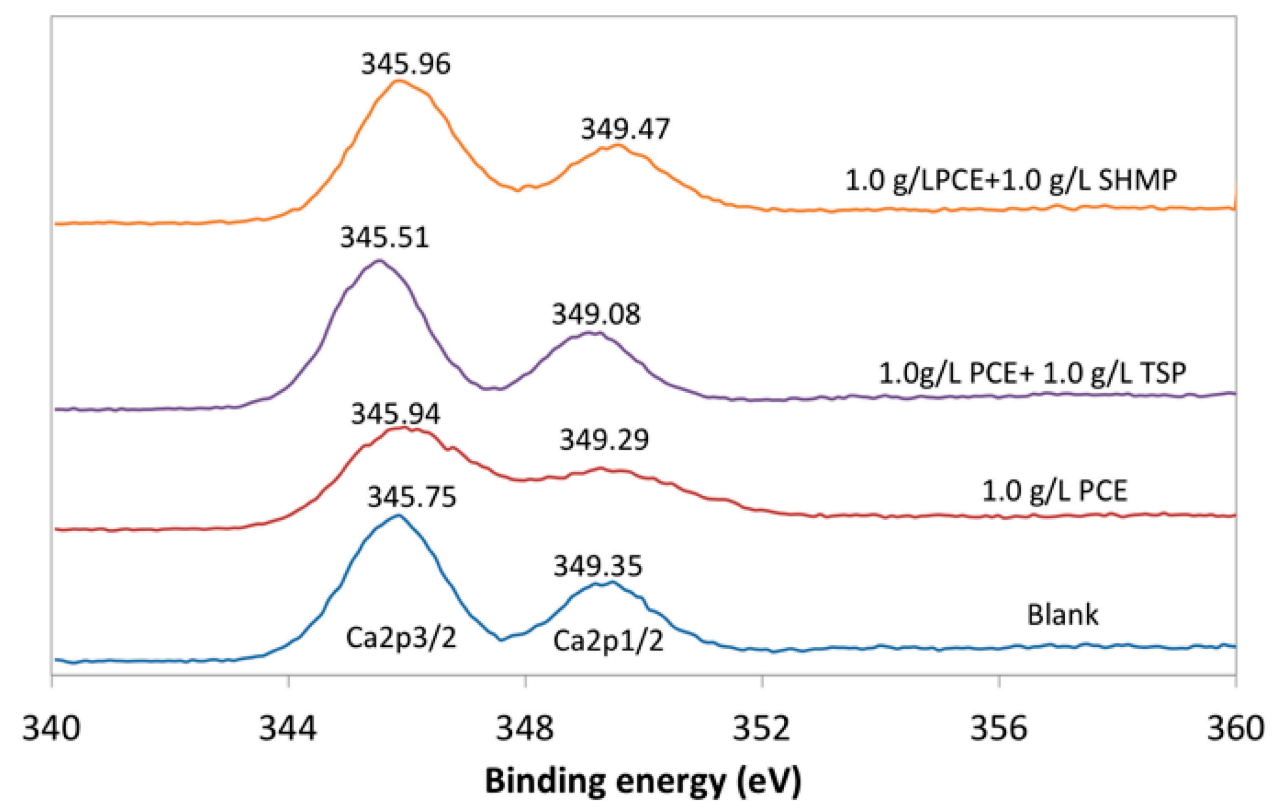

Figure 14. Binding energy of $\mathrm{Ca} 2 \mathrm{p}$ on the surface of cement particle.

\subsection{Dispersion Model}

On the basis of discussion mentioned above, the enhanced dispersion capacity of PCE by SHMP and the reduced dispersion ability resulting from TSP could not be convincingly explained by the retarding effect, competitive adsorption, or thickness of adsorption layers. However, based analysis of composition of adsorption layer, the dispersion models were proposed to reveal the mechanism behind as follow:

Steric hindrance, provided by PEO chain, has been proved as the main force to plasticize the cement particles. In fact, this force mainly depended on amount of S-PCE [62,63]. It was generally believed that a greater amount of S-PCE could provide higher dispersion capacity. However, if PEO were wrapped or covered by hydration products or precipitates, PEO would not be stretched into the solution to efficiently provide the steric hindrance, which meant that the wrapped or covered PCE would be invalided [64-66]. Based on this, the effect of phosphate on formation of S-PCE, which would obviously affect the water/solid interface performance at the very beginning, should be associated with the dispersion of PCE-phosphate system.

In the PCE-TSP system, when the cement was mixed with PCE system, $\mathrm{Ca}^{2+}$ was released into the liquid phase and PCE quickly adsorbed onto surface of cement grains; simultaneously, TSP was precipitated with $\mathrm{Ca}^{2+}$ in the immediate vicinity of cement grains, which could alter the surface performance of these grains, thereby perturbing the adsorption of PCE. A more interesting phenomenon was that TSP would most likely be precipitated on the surface of S-PCE to cover and inactivate the S-PCE, as shown in Figure 15. In that case, PEO might be squeezed and it could not work normally, which meant that the covered S-PCE would be invalided and could not provide dispersion $[64,67]$. In fact, similarity to the PCE covered by hydration products, the covered S-PCE was deemed as the ineffective adsorption. As a consequence, the precipitation of calcium-based phosphate to cover and invalidate the S-PCE was responsible for the decrease in dispersion capacity of the PCE-TSP system. 


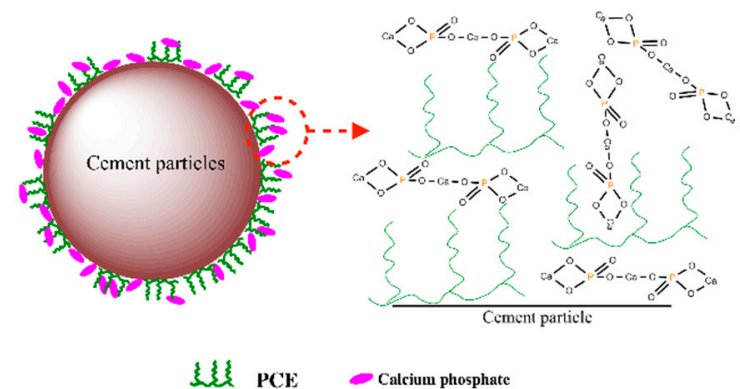

Figure 15. Dispersion model of PCE system with TSP.

In the PCE-SHMP system, SHMP was combined with $\mathrm{Ca}^{2+}$ and $\mathrm{Ca}-\mathrm{O}$ structure on the surface of cement particles. As the competitive adsorption would take place between PCE and SHMP, the adsorption points where PCE had adsorbed could not be adsorbed by SHMP, while PCE could not adsorb onto the point where it had been preferentially adsorbed by SHMP. However, the adsorption ability of SHMP was much stronger than that of PCE, which was proved before and, therefore, the vast majority of SHMP would preferentially adsorb to form the SHMP layer. PCE in solution continuously adsorbed onto the SHMP layer to form a S-PCE layer outside the SHMP layer over time. In other words, most PCE would adsorb onto the surface of the SHMP layer via $\mathrm{Ca}^{2+}$ in solution, as shown in Figure 16, to from the SHMP-Ca-PCE layer. Almost no PCE would be wrapped into the inside layer, which avoids the consumption of PCE caused by hydration products; this could enhance the dispersion efficiency of PCE system, in spite of much less adsorption amount of PCE. As a consequence, it was concluded that the increase in dispersion capacity of PCE-SHMP system was attributed to the enhancement of dispersion efficiency of PCE resulting from the formation of the multiple adsorption layer that was composed of several SHMP layers inside and a PCE layer outside.

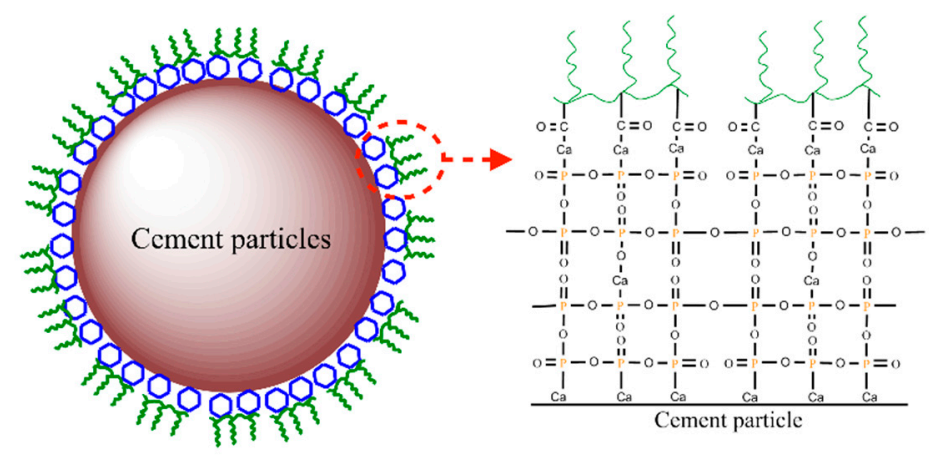

多药 PCE O SHMP

Figure 16. Dispersion model of PCE system with SHMP.

\section{Conclusions}

TSP and SHMP both delayed the cement hydration, impeded the adsorbing process of PCE, and increased the thickness of adsorption layer, while an interesting result was found: TSP reduced the dispersion but SHMP was enhanced.

TSP was quickly precipitated with $\mathrm{Ca}^{2+}$ in the immediate vicinity of the cement particle, which could cover and invalidate the adsorbed PCE, thereby reducing the dispersion of PCE. SHMP was combined with $\mathrm{Ca}^{2+}$ and preferentially adsorbed onto the surface of cement particle, which could form "Inner-phosphate (multi-layers) + Outer-PCE (single layer)" structure, hence enhancing the dispersion.

Author Contributions: Y.Z. contributed to the writing work; H.L. and J.L. contributed to the experiment and data analysis. R.T. also contributed to the writing work and data analysis. 
Funding: This research was funded by Innovation Fund Project of China Electric Power Research Institute "Nano-self-dispersion technology and its mechanism for improving the performance of transmission line concrete" (grant number: GC83-18-001).

Conflicts of Interest: The authors declare that there are no conflicts of interest regarding the publication of this paper.

\section{References}

1. Ferraris, C.F.; Obla, K.H.; Hill, R. The influence of mineral admixtures on the rheology of cement paste and concrete. Cem. Concr. Res. 2001, 31, 245-255. [CrossRef]

2. Peng, J.; Qu, J.; Zhang, J.; Chen, M.; Wan, T. Adsorption characteristics of water-reducing agents on gypsum surface and its effect on the rheology of gypsum plaster. Cem. Concr. Res. 2005, 35, 527-531. [CrossRef]

3. Hanehara, S.; Yamada, K. Rheology and early age properties of cement systems. Cem. Concr. Res. 2008, 38, 175-195. [CrossRef]

4. Liu, T.; Wang, Z.; Zou, D.; Zhou, A.; Du, J. Strength enhancement of recycled aggregate pervious concrete using a cement paste redistribution method. Cem. Concr. Res. 2019, 122, 72-82. [CrossRef]

5. Senff, L.; Labrincha, J.A.; Ferreira, V.M.; Hotza, D.; Repette, W.L. Effect of nano-silica on rheology and fresh properties of cement pastes and mortars. Constr. Build. Mater. 2009, 23, 2487-2491. [CrossRef]

6. Feys, D.; De Schutter, G.; Khayat, K.H.; Verhoeven, R. Changes in rheology of self-consolidating concrete induced by pumping. Mater. Struct. 2016, 49, 4657-4677. [CrossRef]

7. Liu, X.; Ma, B.; Tan, H.; Gu, B.; Zhang, T.; Chen, P.; Li, H.; Mei, J. Effect of aluminum sulfate on the hydration of Portland cement, tricalcium silicate and tricalcium aluminate. Constr. Build. Mater. 2020, 232. [CrossRef]

8. $\mathrm{Ng}, \mathrm{S}$.; Justnes, $\mathrm{H}$. Influence of plasticizers on the rheology and early heat of hydration of blended cements with high content of fly ash. Cem. Concr. Compos. 2016, 65, 41-54. [CrossRef]

9. Ghahari, S.A.; Mohammadi, A.; Ramezanianpour, A.A. Performance assessment of natural pozzolan roller compacted concrete pavements. Case Stud. Constr. Mater. 2017, 7, 82-90. [CrossRef]

10. Ramezanianpour, A.A.; Ghahari, S.A.; Esmaeili, M. Effect of combined carbonation and chloride ion ingress by an accelerated test method on microscopic and mechanical properties of concrete. Constr. Build. Mater. 2014, 58, 138-146. [CrossRef]

11. Shannag, M.J. High strength concrete containing natural pozzolan and silica fume. Cem. Concr. Compos. 2000, 22, 399-406. [CrossRef]

12. Tan, H.; Li, M.; He, X.; Su, Y.; Zhang, J.; Pan, H.; Yang, J.; Wang, Y. Preparation for micro-lithium slag via wet grinding and its application as accelerator in Portland cement. J. Clean. Prod. 2019, 119528. [CrossRef]

13. Kong, F.-R.; Pan, L.-S.; Wang, C.-M.; Zhang, D.-L.; Xu, N. Effects of polycarboxylate superplasticizers with different molecular structure on the hydration behavior of cement paste. Constr. Build. Mater. 2016, 105, 545-553. [CrossRef]

14. Plank, J.; Sakai, E.; Miao, C.W.; Yu, C.; Hong, J.X. Chemical admixtures-Chemistry, applications and their impact on concrete microstructure and durability. Cem. Concr. Res. 2015, 78, 81-99. [CrossRef]

15. Felekoğlu, B.; Sarıkahya, H. Effect of chemical structure of polycarboxylate-based superplasticizers on workability retention of self-compacting concrete. Constr. Build. Mater. 2008, 22, 1972-1980. [CrossRef]

16. Zingg, A.; Winnefeld, F.; Holzer, L.; Pakusch, J.; Becker, S.; Gauckler, L. Adsorption of polyelectrolytes and its influence on the rheology, zeta potential, and microstructure of various cement and hydrate phases. J. Colloid Interface Sci. 2008, 323, 301-312. [CrossRef]

17. Lesage, K.; Cizer, Ö.; Desmet, B.; Vantomme, J.; De Schutter, G.; Vandewalle, L. Plasticising mechanism of sodium gluconate combined with PCE. Adv. Cem. Res. 2015, 27, 163-174. [CrossRef]

18. Wu, Y.; He, T.; Song, X.; Liang, G. Effect of sodium gluconate on polynaphthalene sulfonate adsorption. Adv. Cem. Res. 2011, 23, 249-254. [CrossRef]

19. Tan, H.; Guo, Y.; Zou, F.; Jian, S.; Ma, B.; Zhi, Z. Effect of borax on rheology of calcium sulphoaluminate cement paste in the presence of polycarboxylate superplasticizer. Constr. Build. Mater. 2017, 139, $277-285$. [CrossRef]

20. Bessaies-Bey, H.; Baumann, R.; Schmitz, M.; Radler, M.; Roussel, N. Organic admixtures and cement particles: Competitive adsorption and its macroscopic rheological consequences. Cem. Concr. Res. 2016, 80, 1-9. [CrossRef] 
21. Tan, H.; Huang, J.; Ma, B.; Li, X. Effect of superplasticiser and sodium tripolyphosphate on fluidity of cement paste. Mag. Concr. Res. 2014, 66, 1194-1200. [CrossRef]

22. Li, G.; He, T.; Hu, D.; Huang, R.; Shi, C. Effects of retarders on the fluidity of pastes containing $\beta$-naphthalenesulfonic acid-based superplasticiser. Adv. Cem. Res. 2012, 24, 203-210. [CrossRef]

23. Ma, S.; Li, W.; Zhang, S.; Ge, D.; Yu, J.; Shen, X. Influence of sodium gluconate on the performance and hydration of Portland cement. Constr. Build. Mater. 2015, 91, 138-144. [CrossRef]

24. Zhang, G.; Li, G.; Li, Y. Effects of superplasticizers and retarders on the fluidity and strength of sulphoaluminate cement. Constr. Build. Mater. 2016, 126, 44-54. [CrossRef]

25. Nocun-Wczelik, W.; Czapik, P. Use of calorimetry and other methods in the studies of water reducers and set retarders interaction with hydrating cement paste. Constr. Build. Mater. 2013, 38, 980-986. [CrossRef]

26. Zhang, Y.; Kong, X. Correlations of the dispersing capability of NSF and PCE types of superplasticizer and their impacts on cement hydration with the adsorption in fresh cement pastes. Cem. Concr. Res. 2015, 69, 1-9. [CrossRef]

27. Zhang, Y.-R.; Kong, X.-M.; Lu, Z.-B.; Lu, Z.-C.; Hou, S.-S. Effects of the charge characteristics of polycarboxylate superplasticizers on the adsorption and the retardation in cement pastes. Cem. Concr. Res. 2015, 67, $184-196$. [CrossRef]

28. Tan, H.; Guo, Y.; Ma, B.; Li, X.; Gu, B. Adsorbing Behavior of Polycarboxylate Superplasticizer in the Presence of Ester Group in Side Chain. J. Disper. Sci. Technol. 2017, 38, 743-749. [CrossRef]

29. Shu, X.; Wang, Y.; Yang, Y.; Wang, X.; Zhang, Q.; Zhao, H.; Ran, Q.; Liu, J. Rheological Properties of Cement Pastes with Polycarboxylate Superplasticizers of Varied Backbone Stiffness. J. Mater. Civ. Eng. 2019, 31, 04019092. [CrossRef]

30. Ran, Q.; Somasundaran, P.; Miao, C.; Liu, J.; Wu, S.; Shen, J. Effect of the length of the side chains of comb-like copolymer dispersants on dispersion and rheological properties of concentrated cement suspensions. J. Colloid Interface Sci. 2009, 336, 624-633. [CrossRef]

31. Bey, H.B.; Hot, J.; Baumann, R.; Roussel, N. Consequences of competitive adsorption between polymers on the rheological behaviour of cement pastes. Cem. Concr. Compos. 2014, 54, 17-20. [CrossRef]

32. Li, G.; He, T.; Hu, D.; Shi, C. Effects of two retarders on the fluidity of pastes plasticized with aminosulfonic acid-based superplasticizers. Constr. Build. Mater. 2012, 26, 72-78. [CrossRef]

33. Plank, J.; Winter, C. Competitive adsorption between superplasticizer and retarder molecules on mineral binder surface. Cem. Concr. Res. 2008, 38, 599-605. [CrossRef]

34. Tan, H.; Zou, F.; Ma, B.; Guo, Y.; Li, X.; Mei, J. Effect of competitive adsorption between sodium gluconate and polycarboxylate superplasticizer on rheology of cement paste. Constr. Build. Mater. 2017, 144, 338-346. [CrossRef]

35. Zou, F.; Tan, H.; Guo, Y.; Ma, B.; He, X.; Zhou, Y. Effect of sodium gluconate on dispersion of polycarboxylate superplasticizer with different grafting density in side chain. J. Ind. Eng. Chem. 2017, 55, 91-100. [CrossRef]

36. Lv, S.; Gao, R.; Cao, Q.; Li, D.; Duan, J. Preparation and characterization of poly-carboxymethyl- $\beta$-cyclodextrin superplasticizer. Cem. Concr. Res. 2012, 42, 1356-1361. [CrossRef]

37. Tan, H.; Zou, F.; Ma, B.; Liu, M.; Li, X.; Jian, S. Effect of sodium tripolyphosphate on adsorbing behavior of polycarboxylate superplasticizer. Constr. Build. Mater. 2016, 126, 617-623. [CrossRef]

38. Tan, H.; Zou, F.; Liu, M.; Ma, B.; Guo, Y.; Jian, S. Effect of the Adsorbing Behavior of Phosphate Retarders on Hydration of Cement Paste. J. Mater. Civ. Eng. 2017, 29, 04017088. [CrossRef]

39. Guo, Y.; Ma, B.; Zhi, Z.; Tan, H.; Liu, M.; Jian, S.; Guo, Y. Effect of polyacrylic acid emulsion on fluidity of cement paste. Colloids Surf. A Physicochem. Eng. Asp. 2017, 535, 139-148. [CrossRef]

40. Zhang, C.; Kong, X.; Lu, Z.; Jansen, D.; Pakusch, J.; Wang, S. Pore structure of hardened cement paste containing colloidal polymers with varied glass transition temperature and surface charges. Cem. Concr. Compos. 2019, 95, 154-168. [CrossRef]

41. Tian, H.; Kong, X.; Sun, J.; Wang, D.; Huang, C. Fluidizing effects of polymers with various anchoring groups in cement pastes and their sensitivity to environmental temperatures. J. Appl. Polym. Sci. 2019, 136, 47494. [CrossRef]

42. Tian, H.; Kong, X.; Su, T.; Wang, D. Comparative study of two PCE superplasticizers with varied charge density in Portland cement and sulfoaluminate cement systems. Cem. Concr. Res. 2019, 115, 43-58. [CrossRef]

43. Lu, Z.; Kong, X.; Zhang, C.; Cai, Y. Effect of highly carboxylated colloidal polymers on cement hydration and interactions with calcium ions. Cem. Concr. Res. 2018, 113, 140-153. [CrossRef] 
44. Lu, Z.; Kong, X.; Zhang, C.; Xing, F.; Zhang, Y. Effect of colloidal polymers with different surface properties on the rheological property of fresh cement pastes. Colloids Surf A Physicochem. Eng. Asp. 2017, 520, 154-165. [CrossRef]

45. Kong, X.; Pakusch, J.; Jansen, D.; Emmerling, S.; Neubauer, J.; Goetz-Neuhoeffer, F. Effect of polymer latexes with cleaned serum on the phase development of hydrating cement pastes. Cem. Concr. Res. 2016, 84, 30-40. [CrossRef]

46. Ren, Q.; Jiang, Z.; Li, H.; Zhu, X.; Chen, Q. Fresh and hardened properties of self-compacting concrete using silicon carbide waste as a viscosity-modifying agent. Constr. Build. Mater. 2019, 200, 324-332. [CrossRef]

47. Tan, H.; Zhang, X.; He, X.; Guo, Y.; Deng, X.; Su, Y.; Yang, J.; Wang, Y. Utilization of lithium slag by wet-grinding process to improve the early strength of sulphoaluminate cement paste. J. Clean. Prod. 2018, 205, 536-551. [CrossRef]

48. Liu, M.; Tan, H.; He, X. Effects of nano- $\mathrm{SiO}_{2}$ on early strength and microstructure of steam-cured high volume fly ash cement system. Constr. Build. Mater. 2019, 194, 350-359. [CrossRef]

49. Ahmad, M.R.; Chen, B.; Haque, M.A.; Ali Shah, S.F. Development of a sustainable and innovant hygrothermal bio-composite featuring the enhanced mechanical properties. J. Clean. Prod. 2019, 229, 128-143. [CrossRef]

50. Yousefi Oderji, S.; Chen, B.; Ahmad, M.R.; Shah, S.F.A. Fresh and hardened properties of one-part fly ash-based geopolymer binders cured at room temperature: Effect of slag and alkali activators. J. Clean. Prod. 2019, 225, 1-10. [CrossRef]

51. Chen, P.; Ma, B.; Tan, H.; Liu, X.; Zhang, T.; Qi, H.; Peng, Y.; Yang, Q.; Wang, J. Effects of amorphous aluminum hydroxide on chloride immobilization in cement-based materials. Constr. Build. Mater. 2020, 231, 117171. [CrossRef]

52. Yang, X.; Liu, J.; Li, H.; Xu, L.; Ren, Q.; Li, L. Effect of triethanolamine hydrochloride on the performance of cement paste. Constr. Build. Mater. 2019, 200, 218-225. [CrossRef]

53. Huang, Y.; Xu, C.; Li, H.; Jiang, Z.; Gong, Z.; Yang, X.; Chen, Q. Utilization of the black tea powder as multifunctional admixture for the hemihydrate gypsum. J. Clean. Prod. 2019, 210, 231-237. [CrossRef]

54. Tan,H.; Li, X.; Huang, J.; Ma, B.; Qi, C.; Chaoliang, L. Effect of competitive adsorption between polycarboxylate superplasticiser and sodium tripolyphosphate on cement paste fluidity. Adv. Cem. Res. 2015, 27, 593-600. [CrossRef]

55. AzariJafari, H.; Kazemian, A.; Ahmadi, B.; Berenjian, J.; Shekarchi, M. Studying effects of chemical admixtures on the workability retention of zeolitic Portland cement mortar. Constr. Build. Mater. 2014, 72, 262-269. [CrossRef]

56. Zhang, D.-F.; Ju, B.-Z.; Zhang, S.-F.; He, L.; Yang, J.-Z. The study on the dispersing mechanism of starch sulfonate as a water-reducing agent for cement. Carbohyd. Polym. 2007, 70, 363-368. [CrossRef]

57. Dean, J.A. Lange's Handbook of Chemistry; McGraw-Hill: New York, NY, USA, 1999; Volume 15, p. 848.

58. Lupu, C.; Arvidson, R.S.; Luttge, A.; Barron, A.R. Phosphonate mediated surface reaction and reorganization: Implications for the mechanism controlling cement hydration inhibition. Chem. Commun. 2005, 2354-2356. [CrossRef]

59. Plank, J.; Sachsenhauser, B. Experimental determination of the effective anionic charge density of polycarboxylate superplasticizers in cement pore solution. Cem. Concr. Res. 2009, 39, 1-5. [CrossRef]

60. Zhang, Q.; Ran, Q.; Zhao, H.; Shu, X.; Yang, Y. Effect of counterions on comb-like polycarboxylate conformation in aqueous solutions. J. Disper. Sci. Technol. 2017, 38, 721-728. [CrossRef]

61. Ran, Q.; Qiao, M.; Liu, J. Influence of $\mathrm{Ca}_{2}+$ on the performance of poly(acrylic acid)-g-poly(ethylene glycol) comb-like copolymers in cement suspensions. Iran. Polym. J. 2014, 23, 663-669. [CrossRef]

62. Tan, H.; Guo, Y.; Ma, B.; Gu, B.; Zou, F. Effect of sodium gluconate on clay tolerance of polycarboxylate superplasticiser. Adv. Cem. Res. 2017, 29, 278-286. [CrossRef]

63. Tan, H.; Gu, B.; Jian, S.; Ma, B.; Guo, Y.; Zhi, Z. Improvement of Polyethylene Glycol in Compatibility with Polycarboxylate Superplasticizer and Poor-Quality Aggregates Containing Montmorillonite. J. Mater. Civ. Eng. 2017, 29, 04017131. [CrossRef]

64. Tan, H.; Gu, B.; Guo, Y.; Ma, B.; Huang, J.; Ren, J.; Zou, F.; Guo, Y. Improvement in compatibility of polycarboxylate superplasticizer with poor-quality aggregate containing montmorillonite by incorporating polymeric ferric sulfate. Constr. Build. Mater. 2018, 162, 566-575. [CrossRef]

65. Tan, H.; Guo, Y.; Ma, B.; Huang, J.; Gu, B.; Zou, F. Effect of Sodium Tripolyphosphate on Clay Tolerance of Polycarboxylate Superplasticizer. KSCE J. Civ. Eng. 2018, 22, 2934-2941. [CrossRef] 
66. Zhang, Q.; Ran, Q.; Zhao, H.; Shu, X.; Yang, Y.; Zhou, H.; Liu, J. pH-induced conformational changes of comb-like polycarboxylate investigated by experiment and simulation. Colloid Polym. Sci. 2016, 294, 1705-1715. [CrossRef]

67. Tan, H.; Zhang, X.; Guo, Y.; Ma, B.; Jian, S.; He, X.; Zhi, Z.; Liu, X. Improvement in fluidity loss of magnesia phosphate cement by incorporating polycarboxylate superplasticizer. Constr. Build. Mater. 2018, 165, 887-897. [CrossRef]

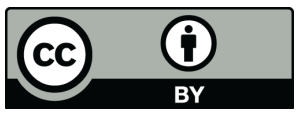

(C) 2019 by the authors. Licensee MDPI, Basel, Switzerland. This article is an open access article distributed under the terms and conditions of the Creative Commons Attribution (CC BY) license (http://creativecommons.org/licenses/by/4.0/). 